\title{
Aggregate Fluctuations and the Cross-sectional Dynamics of Firm Growth*
}

\author{
Sean Holly ${ }^{\dagger} \quad$ Ivan Petrella ${ }^{\ddagger} \quad$ Emiliano Santoro ${ }^{\S}$
}

January 10, 2011

\begin{abstract}
This paper argues that important insights into the business cycle can be obtained by exploring the micro-structure of macroeconomic fluctuations. We fit firm-level growth data with the Asymmetric Exponential Power density, which accounts for asymmetric dispersion and kurtosis on either side of the modal rate. Three novel results are reported. First, firms in the left side of the distribution, that is firms that are growing more slowly or declining, are typically more responsive to aggregate shocks than those in the right side of the distribution. Second, trending behavior in the volatility of firm growth is predominantly driven by increasing dispersion in the growth of highly performing firms. Last, we deliver evidence in support of the view that shifts in the probability mass on either side of the mode may act as important propagators of business fluctuations. The analysis points to financial frictions as one of the mechanisms capable of inducing non-linear micro adjustment consistent with both aggregate and cross-sectional dynamics.
\end{abstract}

JEL classification: C16; E32; G30.

Keywords: Business Cycle, Corporate Growth, Asymmetric Exponential Power Distribution.

${ }^{*}$ We would like to thank Giulio Bottazzi, Tiago Cavalcanti, Jagjit Chadha, Domenico Delli Gatti, Geert Dhaene, Chris Higson, Damjan Pfajfar and seminar participants at the Universities of Cambridge and Trento for helpful comments and suggestions. All remaining errors are our own.

${ }^{\dagger}$ University of Cambridge and CIMF, Cambridge. Address: Faculty of Economics, Austin Robinson Building, Sidgwick Avenue, Cambridge CB3 9DD, United Kingdom. E-mail: sh247@cam.ac.uk.

${ }^{\ddagger}$ Center for Economic Studies, Faculty of Business \& Economics, Katholieke Universiteit Leuven. Address: Naamsestraat 69, 3000 Leuven, Belgium. E-mail: Ivan.Petrella@econ.kuleuven.be.

${ }^{\S}$ ITEMQ, Catholic University of Milan and Department of Economics, University of Copenhagen. Address: Via Necchi 5, 20123, Milan, Italy. E-mail: emiliano.santoro@unicatt.it. 


\section{Introduction}

Business cycle analysis has traditionally focused on co-movements and correlations between major macroeconomic aggregates, such as output, consumption, hours, employment and investment. This paper argues that important insights can be obtained by studying the microstructure of macroeconomic fluctuations. In doing so, we look at firm-level behavior and show that company growth densities change systematically over the business cycle and contribute to shaping macroeconomic fluctuations. Accounting for asymmetry in the cross section of firm growth is crucial to these results.

To explore the micro-structure of business fluctuations we use statistical techniques developed by the literature on industrial dynamics. ${ }^{1}$ Contributors to the empirical strand of this literature have often taken a static approach, fitting firm size and growth distributions on crosssections obtained by pooling data over the time dimension. An alternative line of enquiry has looked at patterns of firm growth and their implications for firm size, as well as at the relationship between firm size and age. ${ }^{2}$ Implicit in these studies is that distributions are either time invariant or may only evolve slowly over time, so that no particular importance is attached to their dynamics. We contrast this view and explore the dynamics of firm growth from a cross-sectional perspective.

We fit UK and US densities of firm growth with the Asymmetric Power Exponential (AEP) distribution. This distribution extends the Exponential Power (EP) class of distributions put forward by Subbotin (1923) and nests the Gaussian and the Laplace as special cases. Most importantly, the AEP allows for different values of the parameters capturing dispersion and kurtosis in the two halves of the density, i.e. above and below the modal growth rate. This feature makes it possible to assess the extent to which the distribution is asymmetric and how asymmetry changes over time.

An important result emerges from the low-frequency evolution of the UK and US densities. In line with previous evidence we detect positive trending behavior in the volatility of the empirical density (see, e.g., Comin and Mulani, 2006). We also identify a downward trend in the kurtosis. However, the low-frequency dynamics of the AEP parameters capturing dispersion and kurtosis on either side of the modal rate suggests that trends in the central moments are predominantly driven by stronger trending behavior on the right hand side of the mode (RHS), as compared to the LHS. These results pose an important challenge to the literature that seeks for an explanation of diverging trends in macroeconomic and microeconomic volatility (see, e.g., Campbell et al., 2001; Comin and Philippon, 2006; Comin and Mulani, 2006), and especially to those interpretations that assume symmetric patterns of change in idiosyncratic risk. Indeed, the asymmetric trending behavior we document is not compatible with symmetric increases in the width of the density of idiosyncratic disturbances.

We then focus on the AEP densities at the business cycle frequency. We report compelling

\footnotetext{
${ }^{1}$ Since the seminal study by Gibrat (1931), several authors have looked at the patterns in the growth of firms and their implications for the distribution of firm sizes. Simon (1955), Hart and Prais (1956), Simon and Bonini (1958), Mansfield (1962), Ijiri and Simon (1964, 1977), Evans (1987b), Hall (1987), Hart and Oulton (1996) and Dunne and Hughes (1994) are some noteworthy examples. Sutton (1997) provides a detailed review of the literature.

${ }^{2}$ Cabral and Mata (2003), Angelini and Generale (2008) and Bottazzi, Secchi, and Tamagni (2010) are notable exceptions, although they aggregate across years to examine firm dynamics and its interplay with financial constraints.
} 
evidence showing that the fitted densities are not time invariant, but exhibit shifts and contortions which are systematically related to the cycle. During a downturn the width of the density decreases on the RHS, while increasing on the LHS. For kurtosis, contractions are characterized by a thinner (fatter) tail on the RHS (LHS). These facts lend support to the findings of Higson et al. $(2002,2004)$, who show that the distribution of firm growth becomes more skewed and leptokurtic in periods of economic slowdown.

A crucial step in the analysis consists of understanding whether changes in the density of firm growth have a role in explaining the business cycle, or whether such movements are to be interpreted as simple cross-sectional projections of aggregate fluctuations. We provide evidence in line with the first view, showing that changes in the probability mass on either side of the modal value display different correlations with the business cycle. We interpret these findings as indicating that firms growing at a different rates may be asymmetrically affected by different potential frictions, which become particularly relevant for the aggregate business cycle when enough firms hit the associated adjustment threshold. ${ }^{3}$ In this case, changes in the probability mass on either side of the density may propagate and amplify macroeconomic fluctuations. By contrast, central moments do not have any predictive power on the business cycle. This evidence emphasizes the importance of accounting for asymmetric patterns of firm growth. On a more general note, a proper understanding of business cycles requires knowledge of the crosssectional distributions as well as the behavior of aggregate economic variables over time (see also McGuckin, 1995, and Haltiwanger, 1997). ${ }^{4}$

In light of these findings, we assess what role financial constraints play in the asymmetric response to real and monetary shocks. A number of empirical and theoretical studies indicate that financial constraints are an important propagator of exogenous and policy-induced shocks. ${ }^{5}$ We evaluate the impact of the external finance premium on firms growing at different rates. It turns out that only firms on the left of the distribution are sensitive to unforecasted changes in the premium. By contrast, firms growing at a rate higher than the density mode are insulated from movements in the vertical spread. This is consistent with the type of threshold effects put forward by Campello, Graham, and Harvey (2010) and Bottazzi, Secchi, and Tamagni (2010) to describe asymmetries in the distribution of firm growth.

Our evidence carries implications for both designing and validating business cycle models. ${ }^{6}$ The representative agent framework explicitly focuses on aggregate behavior, arguing that idiosyncratic shocks to heterogeneous firms cancel out in the aggregate (Lucas, 1977). However, once it is recognized that distributions underlying macroeconomic phenomena are important in determining aggregate outcomes, the RA approach becomes inadequate and heterogeneity needs to be taken into account. State-dependent asymmetry and secular trends in the higher moments suggest that the cancellation of idiosyncratic shocks in the aggregate may be incomplete.

The remainder of the paper is as follows: Section 1 describes the data and provides a

\footnotetext{
${ }^{3} \mathrm{~A}$ vast literature has argued that particular forms of microeconomic adjustment - in particular when they are lumpy - can mean that the higher moments of the cross-sectional distributions of microeconomic actions can affect macroeconomic aggregates (see, e.g., Caballero 1992, and Caballero and Engel 1992, 1993).

${ }^{4}$ A similar point has been made, among others, by Gabaix (2010), who suggests that macroeconomic questions can be clarified by looking at firm-level behavior.

${ }^{5}$ See, e.g., Bernanke and Gertler (1989, 1990), Greenwald and Stiglitz (1988, 1993) and Kiyotaki and Moore (1997).

${ }^{6}$ In this respect, the hypothesis of fat-tailed distributed growth shocks should be embodied in business cycle frameworks, as also emphasized by Fagiolo, Napoletano, and Roventini (2008) and Gaffeo (2008).
} 
preliminary exploration; Section 2 briefly reviews the relevant literature on industrial dynamics and details the statistical methodology employed in the first stage of the parametric analysis; Section 3 explores how the estimated parameters of the AEP distribution vary over time and their interplay with financial factors; Section 4 concludes.

\section{Data Description}

We employ data on UK and US quoted companies. Four main sources are used for the UK: the Cambridge/DTI databank, the London Share Price Database (LSPD), EXSTAT and DATASTREAM. The Cambridge/DTI databank is an accounting dataset. Companies were included only if: they were admitted to the official list of the stock exchange; they were independent companies or company groups; they operated mainly in the UK; their principal activity was manufacturing, distribution, construction, or transport and certain services. EXSTAT and DATASTREAM, dating from 1970, are datasets that collect published company accounts data for UK quoted companies, as well as members of the Times 1000 list of large UK companies. These databases were expanded to include smaller quoted firms from 1975-76. The combination of databases was used to obtain the UK quoted population over the period 1964-2007. The unique source of US data is the COMPUSTAT database of quoted companies accounts, over the 1950-2005 period.

We consider real sales as a proxy for firm size, which is denoted by $s_{i t}{ }^{7}$ We then compute growth rates at the annual frequency, $g_{i t}=\log \left(s_{i t}\right)-\log \left(s_{i t-1}\right)$. The results reported in the main text are obtained by removing firms growing (declining) beyond a $50 \%$ rate. ${ }^{8}$ This choice allows us to exclude outliers and preserve a representative sample, whose average closely tracks the real GDP growth rate.

\subsection{A Preliminary Data Analysis}

Before moving to a detailed parametric analysis of the distribution of firm growth, it is instructive to look at a number of stylized facts. The main point of departure from other contributions is the emphasis on how the cross-sectional distribution of firm-level growth rates varies over time.

We start by showing that there is substantial instability in the empirical distribution of growth rates in the UK and US. We compute, for each pair of consecutive years, the KolmogorovSmirnov (KS) statistics so as to test whether data in different years can be regarded as random samples from the same distribution. As displayed in Figure 1, where the p-values for each pair of consecutive years are reported, distributions are not time invariant. ${ }^{9}$ A second step consists of examining the empirical moments. These are graphed in Figure 2. Average growth rates

\footnotetext{
${ }^{7}$ Nominal sales are deflated by the GDP deflator. Various measures, including firms' assets, the number of employees and real sales have been traditionally used to proxy firm size. The results of various studies have generally been invariant to different proxies (see Evans, 1987a, and Hall, 1987).

${ }^{8}$ The resulting number of observations for the UK ranges from a minimum of 311 to a maximum of 1553 , while for the US we obtain a minimum of 626 and a maximum of 7939 observations. In Appendix A we replicate our analysis with a $[-100,100] \%$ cut-off. The results are not qualitatively affected by extreme observations.

${ }^{9}$ We also compute the Cramer-von Mises and the Kuiper tests. The results (available, upon request, from the authors) are not qualitatively different from those of the KS test. In addition, we also compare the empirical density and the Gaussian. The null hypothesis is always rejected.
} 
track GDP growth quite closely, thus confirming that our sample provides us with a good representation of the dynamics in aggregate activity.

Two aspects are worth mentioning. First, the standard deviation is upward trending in both countries. This finding has been documented, among others, by Comin and Philippon (2006) and Comin and Mulani (2006), who observe diverging trends in the standard deviation of aggregate and firm-level growth in the US. ${ }^{10}$ Second, kurtosis trends downward but eventually converges to a value close to three in the last years of the sample. These secular patterns suggest that the underlying distribution has been slowly moving from being fat-tailed, to a more dispersed and close-to-Normal distribution.

Furthermore, the distributions display shifts and contortions which seem to be correlated with the business cycle. Strikingly, skewness is negative in recessionary periods, reflecting the accumulation of firms in the left hand side of the distribution. This suggests the need to look at distinct patterns of firm growth on either side of the distribution, given that it can rarely be regarded as symmetric. In Table 1 we investigate co-movement between the sample moments and the business cycle. In the first two columns we report measures of static and dynamic correlation (Croux et al., 2001) between each of the moments and aggregate GDP growth. ${ }^{11}$ The third column reports pairwise measures of business cycle concordance capturing the proportion of time that the cycles of two series spend in the same phase (Harding and Pagan, 1999, 2002). ${ }^{12}$ All measures of co-movement show that kurtosis follows a marked pro-cyclical pattern, while standard deviation and skewness behave counter-cyclically in both countries. These facts have been widely documented by Higson et al. $(2002,2004) .{ }^{13}$ It is also worth noting that skewness is more strongly correlated with the business cycle in the UK. By contrast, standard deviation and kurtosis are more strongly correlated (in absolute value) in the US.

Overall, growth rate distributions change over time and their higher moments display sizeable correlations with economic activity. Moreover, trending behavior in standard deviation and kurtosis may have implications for the study of business fluctuations. Nevertheless, this evidence does not provide us with any insight as to how firms on either side of the density behave at both business cycle and lower frequencies and, if asymmetry matters, whether this has implications for the propagation of aggregate shocks. The rest of the analysis is explicitly aimed at addressing these questions.

\section{The Asymmetric Exponential Power Distribution}

Since the seminal work by Gibrat (1931), a vast literature has explored the relationship between firm size and growth. Views have largely converged on the fact that expected firm growth rates

\footnotetext{
${ }^{10} \mathrm{~A}$ time series measure of firm-level growth volatility is used in these studies. Campbell, Lettau, Malkiel, and $\mathrm{Xu}$ (2001) document analogous trends in market and firm-level volatility. However, they adopt a cross-sectional measure.

${ }^{11}$ Dynamic correlation on a frequency band equals the (static) correlation of the band-pass filter series (see Croux et al., 2001, for more details).

${ }^{12}$ For each series different phases are identified by applying the Bry and Boschan (1971) algorithm. McDermott and Scott (2000) show that concordance is symmetric around 0.5. Therefore, for series that are negatively correlated this measure has to be read as a complement to the statistics in Table 1, which measures the proportion of time the two series are in opposite phases of the cycle.

${ }^{13}$ Also Bachmann and Bayer (2009) report evidence on the relationship between the standard deviation of firm growth and the cycle. They show that co-movement is even stronger if total factor productivity is considered instead of firm growth.
} 
are independent of size (the Law of Proportionate Effect or Gibrat's Law) and that firm size densities are well approximated by a Lognormal. ${ }^{14}$ The main implication of this is that assuming that shocks buffeting the log of firm size are independent - the distribution of growth rates converges to a Gaussian, provided that the Central Limit Theorem applies. However, a number of studies have shown that the postulated Normal distribution of growth rates provides a poor fit to the data. Instead, we see that the distribution of growth rates has a characteristic tent-shape (on a log-log scale). Therefore, it has been proposed to fit firm growth densities using a Laplace (or Symmetric Exponential) density. ${ }^{15}$

More recently, researchers have turned their attention to a class of fat-tailed densities, such as the Exponential Power (EP) introduced by Subbotin (1923). ${ }^{16}$ The functional form of the EP density is characterized by three parameters: a location parameter $m$, a scale parameter $a$ (capturing the width of the density) and a shape parameter $b$ (decreasing in the degree of kurtosis). Importantly, the EP density encompasses, as special cases, the Gaussian $(b=2)$ and Laplace $(b=1)$ densities. The lower $b$ is, the fatter the tails are. Therefore, the distribution is commonly regarded as platikurtic for $b>2$ and leptokurtic for $b<2$. Furthermore, the EP density is characterized by exponentially shaped tails that are less fat than those of power-law densities.

The Asymmetric Exponential Power density extends the EP density, allowing for different values of the parameters $a$ and $b$ in the two halves of the density. The resulting density depends on five parameters: a positioning parameter $m$, two scale parameters, one for the values below $m\left(a_{l}\right)$ and one for values above it $\left(a_{r}\right)$, and two shape parameters, $b_{l}$ and $b_{r}$, which characterize the lower and upper tail of the density, respectively. The density reads as:

$$
f_{A E P}\left(x ; m, a_{l}, a_{r}, b_{l}, b_{r}\right)=A^{-1} e^{-\left(\frac{1}{b_{l}}\left|\frac{x-m}{a_{l}}\right|^{b_{l}} \theta(m-x)+\frac{1}{b_{r}}\left|\frac{x-m}{a_{r}}\right|^{b_{r}} \theta(x-m)\right)},
$$

where $\theta(z)$ is the Heaviside step function, $A=a_{l} b_{l}^{\frac{1}{b_{l}}} \Gamma\left(1+\frac{1}{b_{l}}\right)+a_{r} b_{r}^{\frac{1}{b_{r}}} \Gamma\left(1+\frac{1}{b_{r}}\right)$ and $\Gamma(\cdot)$ is the Gamma function. The functional form of $f_{A E P}$ is particularly useful, as it nests the two analytical benchmarks traditionally proposed in the literature on industrial dynamics. Most importantly, it allows for asymmetry in the distribution of firm growth, so that asymmetric patterns of co-movement between the distribution and the cycle can be detected.

\subsection{Scale Dependence}

Prior to our parametric analysis, it is appropriate to rescale growth rates to allow for the possibility that their standard deviation scales with firm size (see Hymer and Pashigian, 1962).

\footnotetext{
${ }^{14}$ However, empirical work has usually found a negative relationship between growth rate variance and firm growth. Hymer and Pashigian (1962) were among the first to report the negative relationship between firm growth volatility and size. In response to this regularity, empirical analyses of Gibrat's law have begun to correct for heteroskedasticity in firm growth rates. An additional important feature of firm growth rates is that they are largely random and do not appear to be correlated over time (Sutton, 1997).

${ }^{15}$ See Stanley, Amaral, Buldyrev, Havlin, Leschorn, Maas, Salinger, and Stanley (1996), Amaral, Buldyrev, Havlin, Leschhorn, Maas, Salinger, Stanley, and Stanley (1997) and Bottazzi, Dosi, Lippi, Pammolli, and Riccaboni (2001), who show that growth rates are distributed according to a tent-shape distribution. Bottazzi and Secchi (2006a) explain this stylized fact by proposing a model in which firms' ability to follow new business opportunities increases with the number of opportunities exploited in the past.

${ }^{16}$ The EP density has proven to be a useful benchmark in a number of recent studies, providing a good fit to cross-sections of firm growth rates (see, e.g., Bottazzi et al., 2002) and times series of growth rates for various OECD countries (Fagiolo et al., 2008)
} 
Following Bottazzi and Secchi (2003), we split each cross-section into 20 quantiles (bins) and compute the standard deviation of the associated growth rates in each bin. Thus, we fit the following relationship, for the $\mathrm{j}^{\text {th }}$ bin in the $\mathrm{t}^{\text {th }}$ year:

$$
\log \left(\sigma_{j}\left(g_{i t}\right)\right)=\alpha_{t}+\beta_{t} \bar{s}_{j t-1}+e_{j t}
$$

where $\sigma_{j}\left(g_{i}\right)$ is the standard deviation of growth rates and $\bar{s}_{j}$ is the average size of firms in the $\mathrm{j}^{\text {th }}$ bin. We assume that the error term $e_{j t}$ is $i . i . d .\left(0, \sigma_{t}^{e}\right)$ across bins and over time. ${ }^{17}$ Finally, we define the rescaled growth rate for the $\mathrm{i}^{\text {th }}$ firm in the $\mathrm{j}^{\text {th }}$ bin as:

$$
\hat{g}_{i t}=\frac{g_{i t}}{\exp \left(\hat{\alpha}_{t}+\hat{\beta}_{t} \bar{s}_{j t-1}\right)}, \quad \forall j, t .
$$

so that (rescaled) growth rates have statistical properties independent of firm size and data of firms in different size quantiles can be pooled together. It is important to stress that the regularities reported in the preliminary data analysis still remain after rescaling.

\section{Time Variation in the Distribution of Firm Growth}

We are now ready to fit the cross-sectional distribution of growth rates with the AEP. ${ }^{18}$ To evaluate the goodness-of-fit of the estimated densities and the statistical significance of their parameters, we carry out a number of tests. We first compute the KS test, so as to evaluate the distance between the estimated AEP density and its empirical counterpart, for each year in the sample. The p-values plotted in Figure 3 show that the null hypothesis is never rejected. We also assess the stability of the fitted densities, computing a likelihood-ratio test according to which the null hypothesis constrains the parameters of the AEP to be the same across consecutive years. Figure $4 \mathrm{a}$ reports the p-values of the test for each year/pair, and shows that the estimated AEP parameters change significantly over time, and in both countries. Finally, Figure $4 \mathrm{~b}$ reports the p-values for the likelihood-ratio test of the symmetry of the distribution. Specifically, we compare the likelihood of the symmetric EP distribution to that of the AEP. The former can be nested in the latter by constraining the shape and scale parameters to be the same in the two halves of the density. For the UK, we often find that the fit of the symmetric EP is comparable to that of the AEP, whereas this is never the case for the US.

These preliminary tests confirm the goodness-of-fit of the statistical model and suggest the presence of time-varying asymmetry in the cross-section of growth rates. Figure 5 reports the estimated coefficients, together with a $68 \%$ confidence interval. The visual impression supports our statistical inference, as the estimated densities can rarely be regarded as symmetric. The right shape parameter is often greater than its LHS counterpart, for both the UK and the US. Furthermore, estimates of the shape and scale parameters on the LHS tend to peak in periods of marked economic slowdown, while the estimated coefficients on the RHS peak during episodes of economic expansion.

It is also interesting to note that pairwise correlations between the AEP parameters are rather similar in the two countries (Table 2). Indeed, strong positive correlation is found

\footnotetext{
${ }^{17}$ Negative scaling emerges throughout the time window considered, although $\hat{\beta}_{t}$ changes substantially over time (see Figure B1 in Appendix B).

${ }^{18}$ Theoretical and computational details for the maximum likelihood estimation are reported in Bottazzi and Secchi (2006b).
} 
between the estimated shape and scale parameters on the same side of the density, whereas the left and right scale parameters are negatively correlated. However, while strong negative correlation is observed between the UK shape parameters, these are weakly correlated in the US.

\subsection{Asymmetries in Firm Growth}

The next step in the analysis consists of exploring the dynamics of the AEP distribution. ${ }^{19}$ Table 3 reports correlation coefficients between the estimated parameters and GDP growth, along with other measures of dynamic correlation and business cycle concordance. Moreover, a test for the presence of a linear trend in the parameters is reported. We observe some clear patterns in the long-run behavior of the AEP coefficients. For both countries it appears that what was initially interpreted as a positive (negative) trend in volatility (kurtosis), appears to be largely associated with stronger trending behavior in the parameters on the RHS of the mode, i.e. that part of the density characterized by firms growing at a pace greater than the modal rate. In fact, both the scale and shape parameters on the RHS of the UK density exhibit an upward sloping trend. As to the US, all the AEP parameters display a positive linear trend. However, trends in the RHS parameters have slopes that are statistically greater than those characterizing their LHS counterparts. ${ }^{20}$ This adds important evidence to recent findings of diverging trends in aggregate and microeconomic volatility (Campbell et al., 2001; Comin and Philippon, 2006; Comin and Mulani, 2006). In particular, our results challenge standard interpretations of this evidence that are based on symmetric patterns of change in idiosyncratic risk (e.g., Campbell et al., 2001). We show that trending behavior in the higher moments is not symmetric about the modal rate. ${ }^{21}$

Turning our attention to the business cycle dimension, we note that both the scale and shape parameters on the RHS of the AEP distribution exhibit positive co-movement with GDP growth, whereas the LHS parameters co-move negatively. Most importantly, parameters on the LHS display stronger (negative) co-movement with economic activity, compared to their respective counterparts on the RHS. ${ }^{22}$

Pro-cyclicality in $b_{r}$ means that the right tail of the distribution is on average thinner during

\footnotetext{
${ }^{19}$ Our two-stage strategy consists of first estimating the AEP density for each year/cross-section and then retrieving time series of the parameters that are used to explore the time variation of the UK and US densities. It could be argued that using estimated regressors in the second stage may potentially bias our results. This occurs when the estimated regressor is a noisy observation of the true unobservable parameter. In Appendix $\mathrm{C}$ we discuss this point extensively, showing that this is not an issue in our analysis, as the noise is typically negligible.

${ }^{20} \mathrm{~A}$ closer look at the graph suggests that a significant trend in the LHS parameters may just emerge as a statistical artifact due to a positive shift in mean. This impression is confirmed by the Quandt-Andrews unknown breakpoint test (Andrews, 1993), which identifies a shift in mean around 1974-1975.

${ }^{21}$ Campbell, Lettau, Malkiel, and Xu (2001) interpret increasing volatility of individual stocks as reflecting an increase in idiosyncratic risk, which implies that the dispersion characterizing the underlying distribution of shocks expands symmetrically around its mean.

${ }^{22}$ Whereas the direction of co-movement between different AEP parameters and the cycle are simliar across countries, there are some quantitative differences. The absolute difference in the correlations between the LHS AEP parameters and GDP growth is much higher in the UK than the US, implying stronger (negative) countercyclicality in skewness. For the US, parameters estimated on either side of the density display stronger comovement with the cycle than their counterparts in the UK, a pattern confirmed by stronger correlation with the cycle for the standard deviation and kurtosis in the US.
} 
expansions. The opposite applies to the left tail, which is composed of declining firms. Moreover, as the scale parameters index the width of the density on either side of $m$, evidence of a procyclical (counter-cyclical) $a_{r}\left(a_{l}\right)$ signals that during expansionary periods dispersion in the growth performance increases (decreases) on the RHS (LHS) of the mode. These findings help to uncover the mechanism initially conjectured by Higson et al. $(2002,2004)$ on the presence of counter-cyclical skewness. During a downturn, diminishing dispersion on the RHS is coupled with increasing dispersion on the LHS. Thus, a contraction translates into a density that shifts to the left (such a movement is captured by a drop in $m$ ) and a relative increase in the probability mass on the LHS. As to kurtosis, contractions are characterized by a thinner (fatter) tail on the RHS (LHS).

The remainder of the paper is aimed at deepening our understanding of the connection between the time variation in the AEP distribution and the business cycle, and at identifying a mechanism capable of generating a stronger correlation between firms in the left side of the distribution and macroeconomic fluctuations.

\subsection{On the Real Effects of Asymmetry}

The analysis so far has revealed some distinct patterns in the co-movement between the distribution of growth rates and the business cycle. Although interesting, this evidence is still uninformative about whether changes in the density have a role in explaining aggregate fluctuations, or whether such movements are to be interpreted as simple cross-sectional manifestations of the business cycle. The first interpretation reflects our standpoint. As stressed by Haltiwanger (1997), non-linear micro adjustment in combination with micro heterogeneity may have important implications for aggregate fluctuations. ${ }^{23}$ In this respect, heterogeneity in output, employment, and investment growth rates within sectors implies a large, continuous pace of reallocation of real activity across production sites. ${ }^{24}$ Such reallocation may involve substantial frictions at the root of non-linear micro adjustment. In these cases, the impact of an aggregate shock depends on where individual firms are with respect to their adjustment thresholds, which determines time-varying elasticities of macroeconomic aggregates to aggregate shocks.

In light of these considerations, we argue that changes in the distribution of company growth rates may be relevant in shaping aggregate fluctuations to the extent that they reflect non-trivial interaction between heterogeneity in firm-level growth and non-linear micro adjustment mechanisms. To this end, it is useful to think of some frictions capable of producing asymmetric patterns over the range of growth, such as non-convexities affecting firms' decisions on, say, investment, inventories and labor demand, as well as irreveribilities (e.g., investment and market exit) and financial frictions (e.g., the financial accelerator effect). We argue that when a substantial part of the probability mass hits the threshold associated with such frictions over the range of growth, changes in the density may act as important propagators and amplifiers of macroeconomic fluctuations.

\footnotetext{
${ }^{23}$ Also King and Thomas (2006) show that when discrete adjustment at the micro level matters, aggregate outcomes are driven by changes in both the intensive and extensive margin, with the latter arising from changes in the distribution of plants at the time of production. These considerations have led many to develop macroeconomic models that explicitly consider cross-sectional distributions of plants and firms (see, among others, Bachmann et al., 2008, Khan and Thomas 2003, 2007, 2008, and Veracierto, 2002, 2008).

${ }^{24}$ Studies on longitudinal establishment data show that heterogeneity is a key feature of firm-level growth (see, e.g, Davis et al., 1996).
} 
We test these conjectures with further analysis. We start by looking at pairwise bivariate Granger Causality tests between aggregate growth and various statistics from the empirical and fitted densities. Table 4 asks whether central moments from the empirical density lead aggregate fluctuations. Overall, no particular predictive power can be attributed to variations in the empirical density when these are captured by changes in the central moments. By contrast, the behavior of central moments generally lags the cycle, thus suggesting that changes in the density may just be a projection of aggregate fluctuations onto the cross-section. ${ }^{25}$ However, as discussed at different stages of the analysis, focusing on central moments might overshadow information connected with the emergence of asymmetric patterns in firm growth. In fact, Table 5 indicates that some of the AEP parameters display leading properties with respect to business cycle fluctuations. Some interesting differences arise with respect to the evidence based on the central moments. The results for the UK reveal that an increase in the probability mass on the RHS of the density, reflected by changes in both the scale and shape parameters, lead expansionary phases. For the US it is the overall width of the density (captured by both the right and left scale parameters) and the mode that display leading properties with respect to business cycle fluctuations. Importantly, movements in the right scale parameter tend to predict positive aggregate output growth in the next period, whereas causality never runs in the opposite direction. This confirms that increasing dispersion on the RHS of the mode, which reflects increasing probability mass in the same region over the range of growth, reinforces and propagates expansionary phases. Such predictions are shared by both UK and US data.

The last step in the analysis is aimed at identifying a mechanism consistent with the asymmetric behavior uncovered so far.

\subsection{Asymmetries and Financial Frictions}

In recent years, a renewed interest in the role of the credit channel in propagating and amplifying exogenous and policy-induced disturbances has returned to the fore. This channel predicts that in the presence of asymmetric information between lenders and borrowers and imperfect enforceability of financial contracts, a wedge emerges between the cost of external funds and the opportunity cost of internal funds - the external finance premium. Advocates of the credit view claim that monetary policy can affect the size of the external finance premium and, in turn, the availability of credit to financially constrained firms. ${ }^{26}$ Exploring this mechanism in greater detail, under a longitudinal perspective, can provide us with a deeper insight into the microstructure of aggregate fluctuations. In fact, we argue that greater responsiveness of firms located on the LHS of the density can be explained by financing constraints, which are likely to be more stringent for declining firms. ${ }^{27}$

Gertler and Lown (2000) propose the vertical spread between the yield of corporate bonds of differing risk as a reliable proxy for the external finance premium. The vertical spread, denoted by $E F P_{t}$, is defined as the difference between Moody's seasoned BAA corporate bond yield and

\footnotetext{
${ }^{25}$ This evidence holds for all UK cross-sectional moments, whereas the skewness in the US density generally anticipates the cycle.

${ }^{26}$ See, e.g., Greenwald and Stiglitz $(1988,1993)$, Bernanke and Gertler (1989, 1990), and Kiyotaki and Moore (1997).

${ }^{27}$ The idea that financing constraints might be at the root of observed asymmetries in the size distribution was initially explored in Cabral and Mata (2003), who argue that financial frictions can explain, to some extent, skewed size distributions that are typically observed in young cohorts of firms.
} 
10 year treasury bond yield. ${ }^{28}$

A dynamic relationship between each of the AEP parameters and the contemporaneous value of the vertical spread is fitted: ${ }^{29}$

$$
\left(1-\gamma_{1}^{x} L-\gamma_{2}^{x} L^{2}\right) x_{t}=\alpha_{0}^{x}+\beta_{1}^{x} E F P_{t}+e_{t}^{x}, \quad x_{t}=\left\{m_{t}, a_{l t}, a_{r t}, b_{l t}, b_{r t}\right\} .
$$

The resulting estimates are reported in Table 6 and suggest that the vertical spread has no explanatory power for the AEP parameters on the RHS. Thus, financial frictions do not produce any statistically significant influence on firms experiencing growth beyond the modal rate. Conversely, the spread exerts a positive impact on both the scale and shape parameters on the LHS of the modal rate. This evidence is in line with what we might expect on a priori grounds. As the premium behaves counter-cyclically, a positive $\hat{\beta}_{1}^{x}\left(x=\left\{a_{l}, b_{l}\right\}\right)$ signals that a rise in $E F P_{t}$ is associated with decreasing kurtosis and increasing dispersion on the LHS of the density, which is what we observe during contractions.

Overall, this evidence suggests that financial frictions may be at the root of non-linear micro adjustment mechanisms consistent with the asymmetric patterns of firm growth. Thus, contortions in the cross-sectional density can be explained by the asymmetric influence of financial factors on firms growing at different rates. In fact, it may well be the case that while heavily declining firms are severely constrained in the access to external finance, firms growing at a fast pace can rely on a sufficient degree of internally generated funds and, whenever they seek for external finance, they can offer good collateral.

The role of financing constraints in driving asymmetric patterns of growth has recently received empirical support by Bottazzi, Secchi, and Tamagni (2010), who show that financing constraints, proxied by an explicit credit rating index, significantly affect firms' performance and operate through several channels. In the short-run, along with reducing expected growth at the firm-level, financing constraints may drive asymmetric "threshold effects", either preventing potentially fast growing firms from exploiting growth opportunities or depressing even further the growth prospects of firms experiencing poor growth. Campello, Graham, and Harvey (2010) also point to threshold effects as an important element in firm dynamics in the current financial crisis.

\section{Concluding Remarks}

This paper has analyzed cross-sectional distributions of firm growth and their evolution over time, using data for the UK and the US. Our results point to a correlation between the higher moments of the empirical distributions and aggregate fluctuations. Specifically, whereas skewness is counter-cyclical, standard deviation and kurtosis are pro-cyclical.

We then fit the Asymmetric Exponential Power (AEP) distribution to the growth of firms. The main feature of this function is that it allows for asymmetry on either side of the modal rate in both kurtosis and the width of the distribution. We examine how the cross-sectional distributions vary over time at both business-cycle and secular frequencies. Three main conclusions are reached.

\footnotetext{
${ }^{28}$ Unfortunately, it has only been possible to compute the vertical spread for the US, because analogous data are not available for the UK.

${ }^{29}$ Estimation is performed by GMM, with a Newey-West covariance matrix and automatic lag-selection. A preliminary analysis reveals that the vertical spread fails to Granger-cause any of the AEP parameters. Therefore, past values of the spread represent a perfect instrument in (4).
} 
First, we find asymmetric trends in both volatility and kurtosis on either side of the modal rate of growth. These findings add to recent evidence of diverging trends in aggregate and microeconomic volatility (e.g., Comin and Mulani, 2006) and challenge standard interpretations based on symmetric patterns of change in idiosyncratic risk.

Secondly, asymmetry is a distinctive feature at business cycle frequencies. During a downturn the width of the AEP density decreases on the RHS, while increasing on the LHS. For kurtosis, contractions are characterized by a thinner (fatter) tail on the RHS (LHS). These results add to the findings of Higson et al. $(2002,2004)$, who show that the cross section becomes more skewed and leptokurtic in periods of economic slowdown.

Thirdly, we find that changes in the distribution are not simple projections of aggregate activity onto the cross-sectional spectrum of growth, but contain important information to predict business fluctuations. Asymmetric changes in the probability mass on either side of the mode may act as important amplifiers/attenuators of aggregate activity. By contrast, the central moments do not carry any predictive power with respect to the cycle. Finally, we provide evidence suggesting that the greater responsiveness of the left side of the distribution is consistent with financing constraints, which can be more stringent for declining firms. We show that the premium for external finance exerts a strong positive impact on the AEP parameters on the LHS of the modal rate, while playing no role on the RHS. 


\section{References}

Amaral, L., S. Buldyrev, S. Havlin, H. Leschhorn, P. Maas, M. Salinger, E. StanLey, and M. Stanley (1997): "Scaling Behavior in Economics: Empirical Results for Company Growth," Journal de Physique, 7, 621-633.

Andrews, D. W. K. (1993): "Tests for Parameter Instability and Structural Change with Unknown Change Point," Econometrica, 61(4), 821-56.

Angelini, P., and A. Generale (2008): "On the Evolution of Firm Size Distributions," American Economic Review, 98(1), 426-38.

Bachmann, R., and C. Bayer (2009): "The Cross-section of Firms over the Business Cycle: New Facts and a DSGE Exploration," CESifo Working Paper Series 2810, CESifo Group Munich.

Bachmann, R., R. J. Caballero, and E. Engel (2008): "Aggregate Implications of Lumpy Investment: New Evidence and a DSGE Model," Cowles Foundation Discussion Papers 1566R, Cowles Foundation for Research in Economics, Yale University.

Bernanke, B., and M. Gertler (1989): "Agency Costs, Net Worth, and Business Fluctuations," American Economic Review, 79(1), 14-31.

(1990): "Financial Fragility and Economic Performance," The Quarterly Journal of Economics, 105(1), 87-114.

Bottazzi, G. (2004): "Subbotools User's Manual," mimeo, LEM, Pisa, Italy.

Bottazzi, G., E. Cefis, and G. Dosi (2002): "Corporate growth and industrial structures: some evidence from the Italian manufacturing industry," Industrial and Corporate Change, 11(4), 705-723.

Bottazzi, G., G. Dosi, M. Lippi, F. Pammolli, and M. Riccaboni (2001): "Innovation and corporate growth in the evolution of the drug industry," International Journal of Industrial Organization, 19(7), 1161-1187.

Bottazzi, G., and A. Secchi (2003): "Common Properties and Sectoral Specificities in the Dynamics of U.S. Manufacturing Companies," Review of Industrial Organization, 23(3), 217232.

(2006a): "Explaining the Distribution of Firm Growth Rates," RAND Journal of Economics, 37(2), 235-256.

(2006b): "Maximum Likelihood Estimation of the Symmetric and Asymmetric Exponential Power Distribution," LEM Papers Series 2006/19, Laboratory of Economics and Management (LEM), Sant'Anna School of Advanced Studies, Pisa, Italy.

Bottazzi, G., A. Secchi, and F. Tamagni (2010): "Financial Constraints and Firm Dynamics," Discussion Papers 2010/99, Dipartimento di Scienze Economiche (DSE), University of Pisa, Pisa, Italy. 
Bry, G., And C. Boschan (1971): Cyclical Analysis of Time Series: Selected Procedures and Computer Programs. UMI.

Caballero, R. J. (1992): "A Fallacy of Composition," American Economic Review, 82(5), 1279-92.

Caballero, R. J., and E. M. R. A. Engel (1992): "Beyond the Partial-Adjustment Model," American Economic Review, 82(2), 360-64.

Caballero, R. J., and E. M. R. A. Engel (1993): "Microeconomic Adjustment Hazards and Aggregate Dynamics," The Quarterly Journal of Economics, 108(2), 359-83.

Cabral, L. M. B., and J. Mata (2003): "On the Evolution of the Firm Size Distribution: Facts and Theory," American Economic Review, 93(4), 1075-1090.

Campbell, J. Y., M. Lettau, B. G. Malkiel, and Y. Xu (2001): "Have Individual Stocks Become More Volatile? An Empirical Exploration of Idiosyncratic Risk," Journal of Finance, $56(1), 1-43$.

Campello, M., J. R. Graham, and C. R. Harvey (2010): "The real effects of financial constraints: Evidence from a financial crisis," Journal of Financial Economics, 97(3), 470487.

Comin, D., and S. Mulani (2006): "Diverging Trends in Aggregate and Firm Volatility," The Review of Economics and Statistics, 88(2), 374-383.

Comin, D. A., and T. Philippon (2006): "The Rise in Firm-Level Volatility: Causes and Consequences," in NBER Macroeconomics Annual 2005, Volume 20, NBER Chapters, pp. 167-228. National Bureau of Economic Research, Inc.

Croux, C., M. Forni, and L. Reichlin (2001): "A Measure Of Comovement For Economic Variables: Theory And Empirics," The Review of Economics and Statistics, 83(2), 232-241.

Davis, S. J., J. Haltiwanger, And S. C. Schuh (1996): Job Creation and Destruction. MIT Press.

Dunne, P., And A. Hughes (1994): "Age, Size, Growth and Survival: UK Companies in the 1980s," Journal of Industrial Economics, 42(2), 115-40.

Evans, D. S. (1987a): "The Relationship between Firm Growth, Size, and Age: Estimates for 100 Manufacturing Industries," Journal of Industrial Economics, 35(4), 567-81.

(1987b): "Tests of Alternative Theories of Firm Growth," Journal of Political Economy, $95(4), 657-74$.

Fagiolo, G., M. Napoletano, and A. Roventini (2008): "Are output growth-rate distributions fat-tailed? some evidence from OECD countries," Journal of Applied Econometrics, 23(5), 639-669.

Fuller, W. A. (1987): Measurement Error Models. John Wiley and Sons. 
Gabaix, X. (2010): "The Granular Origins of Aggregate Fluctuations," Econometrica 15286, Forthcoming.

Gaffeo, E. (2008): "Lévy-Stable Productivity Shocks," Macroeconomic Dynamics, 12(03), $425-443$.

Gertler, M., And C. S. Lown (2000): "The Information in the High Yield Bond Spread for the Business Cycle: Evidence and Some Implications," NBER Working Papers 7549, National Bureau of Economic Research, Inc.

Gibrat, R. (1931): "Les Inégalités Economiques, Applications: Aux Inégalités des Richesses, à la Concentration des Entreprises, aux Populations des Ville, aux Statistiques des Familles, etc., d'une Loi Nouvelle, la Loi de l'Effet Proportionnel.," Librarie du Recueil Sirey, Paris.

Greenwald, B. C., and J. E. Stiglitz (1988): "Imperfect Information, Finance Constraints and Business Fluctuations," in Finance Constraints, Expectations and Macroeconomics, ed. by M. Kohn, and S. Tsiang, pp. 103-140. Oxford University Press.

(1993): "Financial Market Imperfections and Business Cycles," The Quarterly Journal of Economics, 108(1), 77-114.

Hall, B. H. (1987): "The Relationship between Firm Size and Firm Growth in the U.S. Manufacturing Sector," Journal of Industrial Economics, 35(4), 583-606.

Haltiwanger, J. C. (1997): "Measuring and analyzing aggregate fluctuations: the importance of building from microeconomic evidence," St Louis FED Review, (May), 55-78.

Harding, D., and A. Pagan (1999): "Knowing the Cycle," Melbourne Institute Working Paper Series wp1999n12, Melbourne Institute of Applied Economic and Social Research, The University of Melbourne.

- (2002): "Dissecting the cycle: a methodological investigation," Journal of Monetary Economics, 49(2), 365-381.

Hart, P., and S. Prais (1956): "The Analysis of Business Concentration: a Statistical Approach," Journal of the Royal Statistical Sociaety. Series A, (119), 150-191.

Hart, P. E., and N. Oulton (1996): "Growth and Size of Firms," Economic Journal, 106(438), 1242-52.

Higson, C., S. Holly, and P. Kattuman (2002): "The cross-sectional dynamics of the US business cycle: 1950-1999," Journal of Economic Dynamics and Control, 26(9-10), 1539-1555.

Higson, C., S. Holly, P. Kattuman, and S. Platis (2004): "The Business Cycle, Macroeconomic Shocks and the Cross-Section: The Growth of UK Quoted Companies," Economica, 71(281), 299-318.

Hymer, S., and P. Pashigian (1962): "Firm Size and Rate of Growth," Journal of Political Economy, 70, 556.

IjIRI, Y., ANd H. A. Simon (1964): "Business Firms Growth and Size," American Economic Review, 54(2), 77-89. 
(1977): Skew Distributions and the Sizes of Business Firms. North-Holland.

Khan, A., and J. K. Thomas (2003): "Nonconvex factor adjustments in equilibrium business cycle models: do nonlinearities matter?," Journal of Monetary Economics, 50(2), 331-360.

(2007): "Inventories and the Business Cycle: An Equilibrium Analysis of (S,s) Policies," American Economic Review, 97(4), 1165-1188.

(2008): "Idiosyncratic Shocks and the Role of Nonconvexities in Plant and Aggregate Investment Dynamics," Econometrica, 76(2), 395-436.

King, R. G., and J. K. Thomas (2006): "Partial Adjustment Without Apology," International Economic Review, 47(3), 779-809.

Kiyotaki, N., And J. Moore (1997): "Credit Cycles," Journal of Political Economy, 105(2), $211-48$.

LuCAS, R. E. (1977): "Understanding business cycles," Carnegie-Rochester Conference Series on Public Policy, 5(1), 7-29.

Mansfield, E. (1962): "Entry, Gibrat's law, Innovation and the Growth of Firms," American Economic Review, 52(5), 1023-1051.

McDermott, C. J., And A. Scott (2000): "Concordance in Business Cycles," IMF Working Papers 00/37, International Monetary Fund.

McGuckin, R. H. (1995): "Establishment Microdata for Economic Research and Policy Analysis: Looking beyond the Aggregates," Journal of Business 85 Economic Statistics, 13(1), $121-26$.

Pagan, A. (1984): "Econometric Issues in the Analysis of Regressions with Generated Regressors," International Economic Review, 25(1), 221-47.

Simon, H. (1955): "On a Class of Skew Distribution Functions," Biometrika, 27, 425-440.

Simon, H. A., And C. P. Bonini (1958): "The Size Distribution of Business Firms," American Economic Review, 48(4), 607-617.

Stanley, M., L. Amaral, S. Buldyrev, S. Havlin, H. Leschorn, P. Maas, M. Salinger, and E. Stanley (1996): "Scaling Behavior in the Growth of Companies," Nature, 379, 804-807.

Subbotin, M. (1923): "On the Law of Frequency of Error," Matematicheskii Sbornik, 31, 296-301.

Sutton, J. (1997): “Gibrat's Legacy,” Journal of Economic Literature, 35(1), 40-59.

Veracierto, M. (2008): "Firing Costs And Business Cycle Fluctuations," International Economic Review, 49(1), 1-39.

Veracierto, M. L. (2002): "Plant-Level Irreversible Investment and Equilibrium Business Cycles," American Economic Review, 92(1), 181-197. 
Zellner, A. (1970): "Estimation of Regression Relationships Containing Unobservable Independent Variables," International Economic Review, 11(3), 441-54. 


\section{Figures and Tables}

FIGURE 1. KOLMOGOROV-SMIRNOV TESTS FOR EACH PAIR OF CONSECUTIVE YEARS
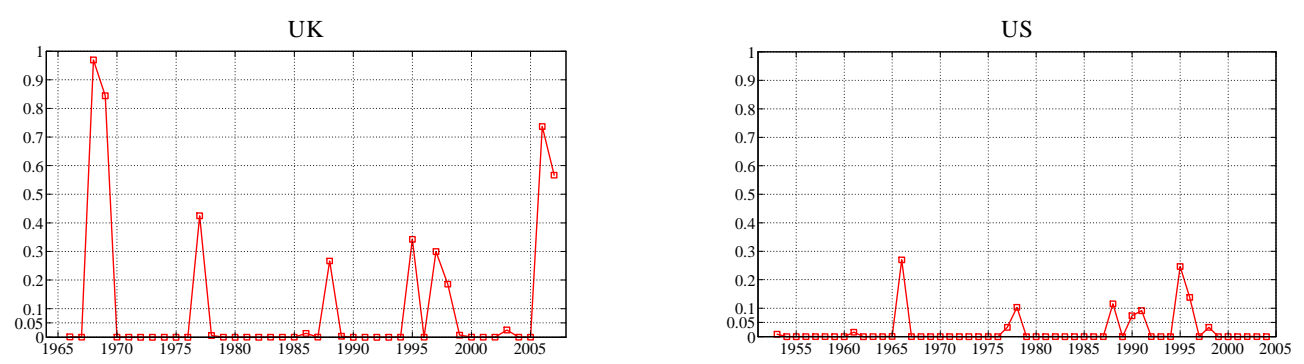

Notes: Figure 1 reports the p-values for the Kolmogorov-Smirnov test. The null hypothesis is that data for different years are random draws from the same continuous distribution. Values lower than the chosen significance value $(5 \%)$ justify our estimation of different cross-sectional distributions for each year. 

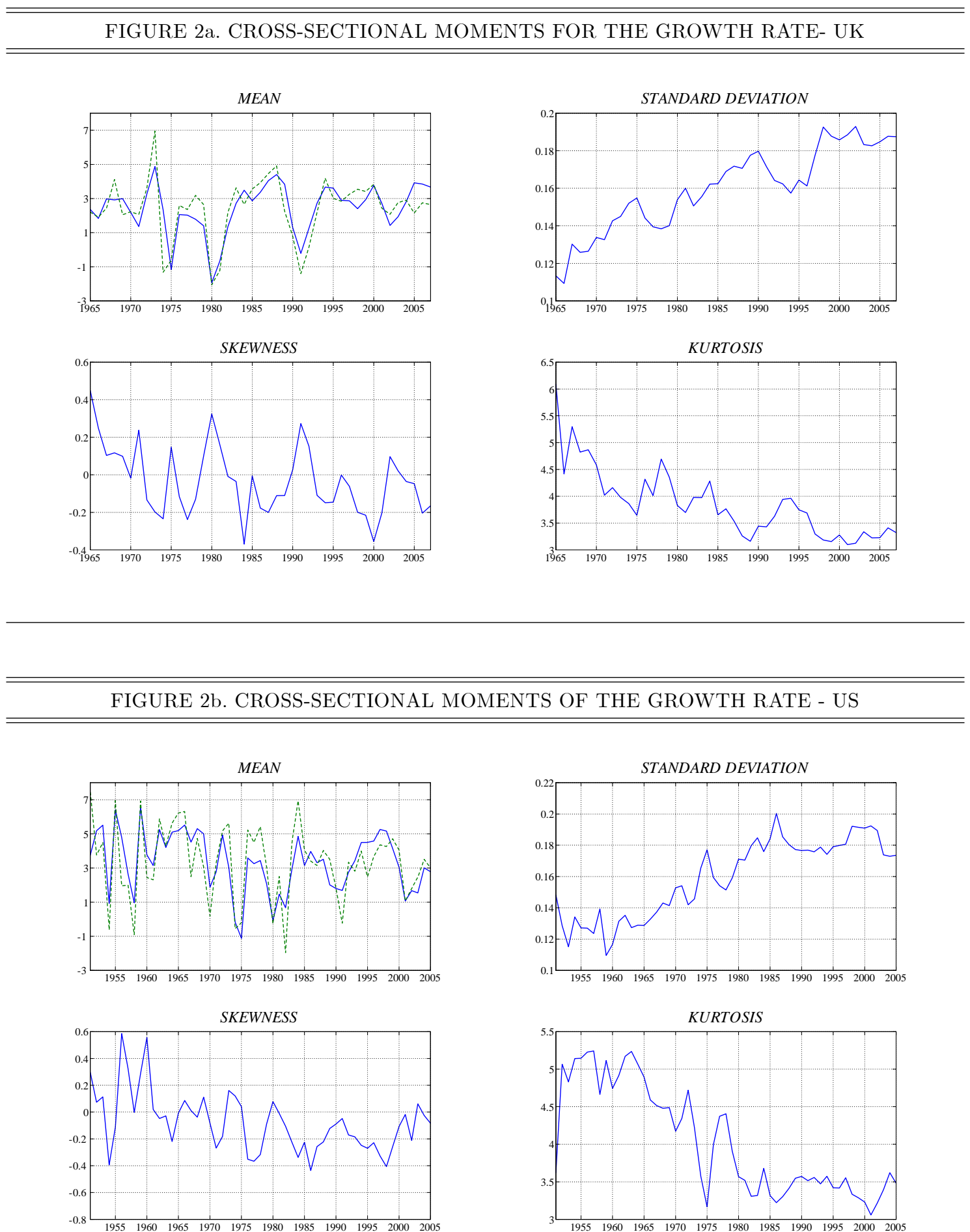

Notes: The dashed (green) line is the GDP growth rate. The continuous (blue) lines are empirical moments of the cross section in each year. 

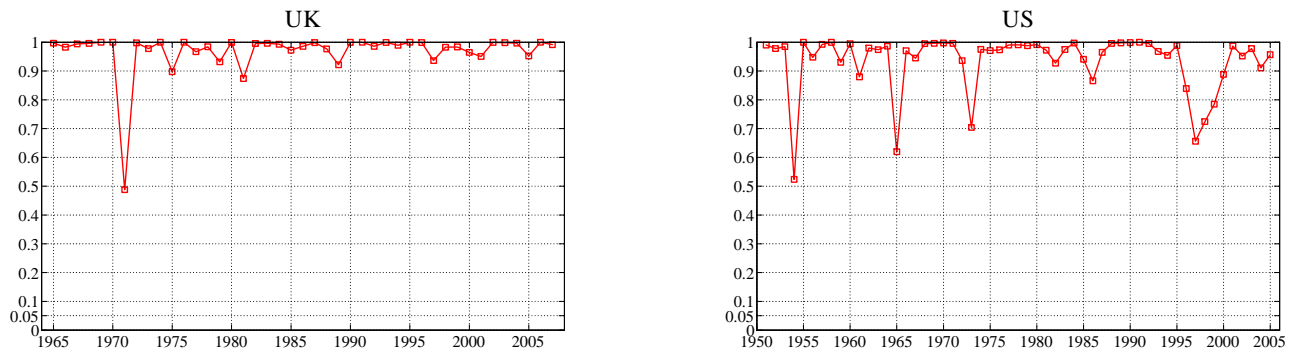

Notes: Each figure reports the p-values associated with the Kolmogorov-Smirnov goodness-of-fit test. Exact p-values are estimated by bootstrapping the distribution of the test statistics under the null hypothesis, with sample size equal to those of the empirical sample. The bootstrap sample size is 5000 . 


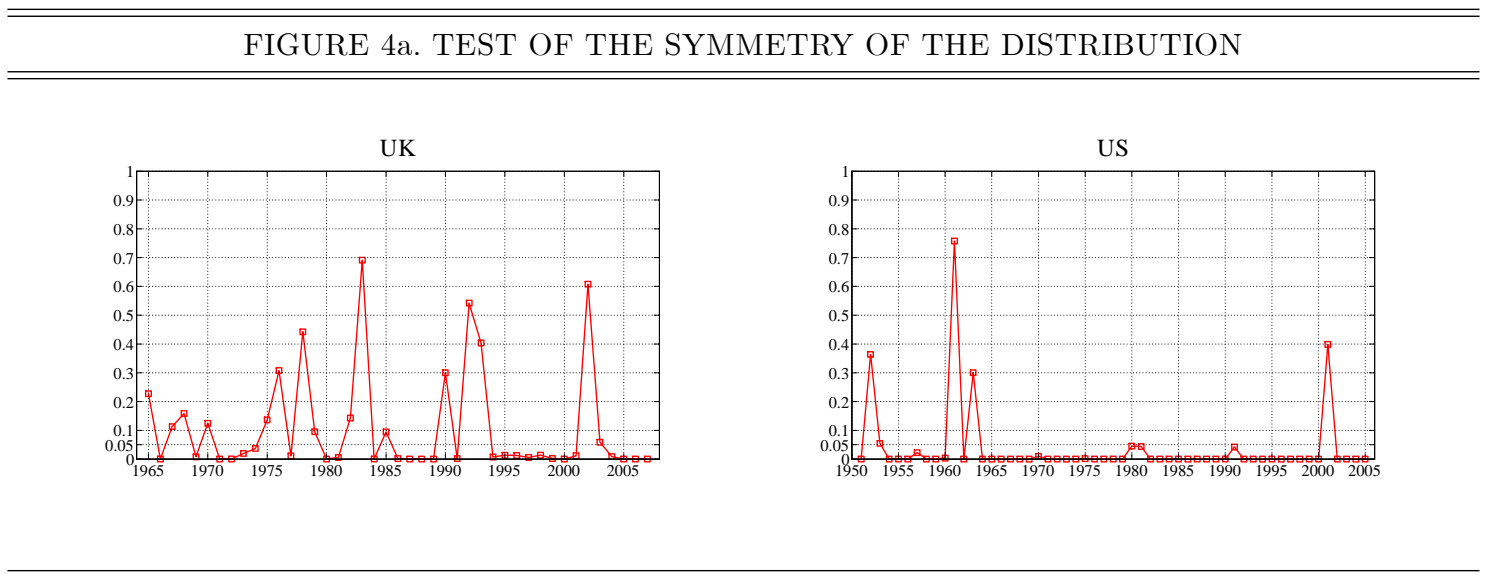

Notes: Each figure reports the p-values of the likelihood-ratio test of the symmetry of the distribution. We compare the likelihood of the symmetric exponential power (EP) distribution to that of the AEP. The former can be nested in the latter by constraining the shape and scale parameters to be the same in the two halves of the density.

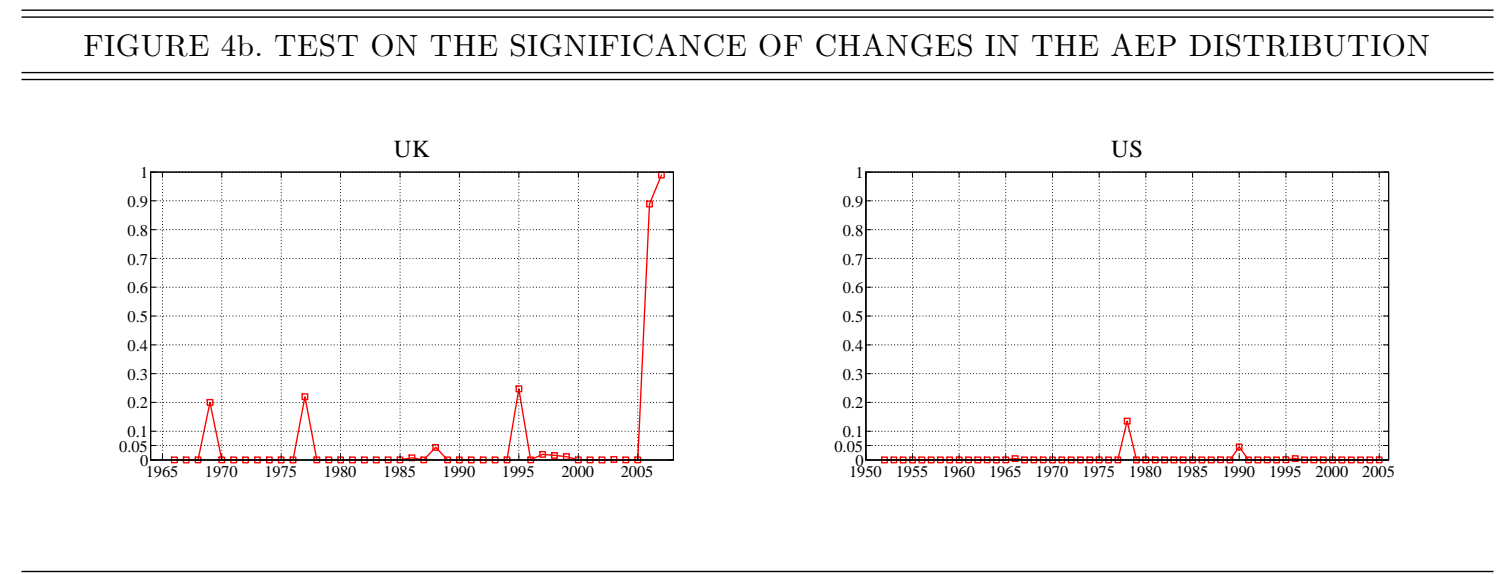

Notes: Each figure reports the p-values for the likelihood-ratio tests. The null hypothesis constrains the parameters of the AEP to be the same as those estimated in the previous year. 


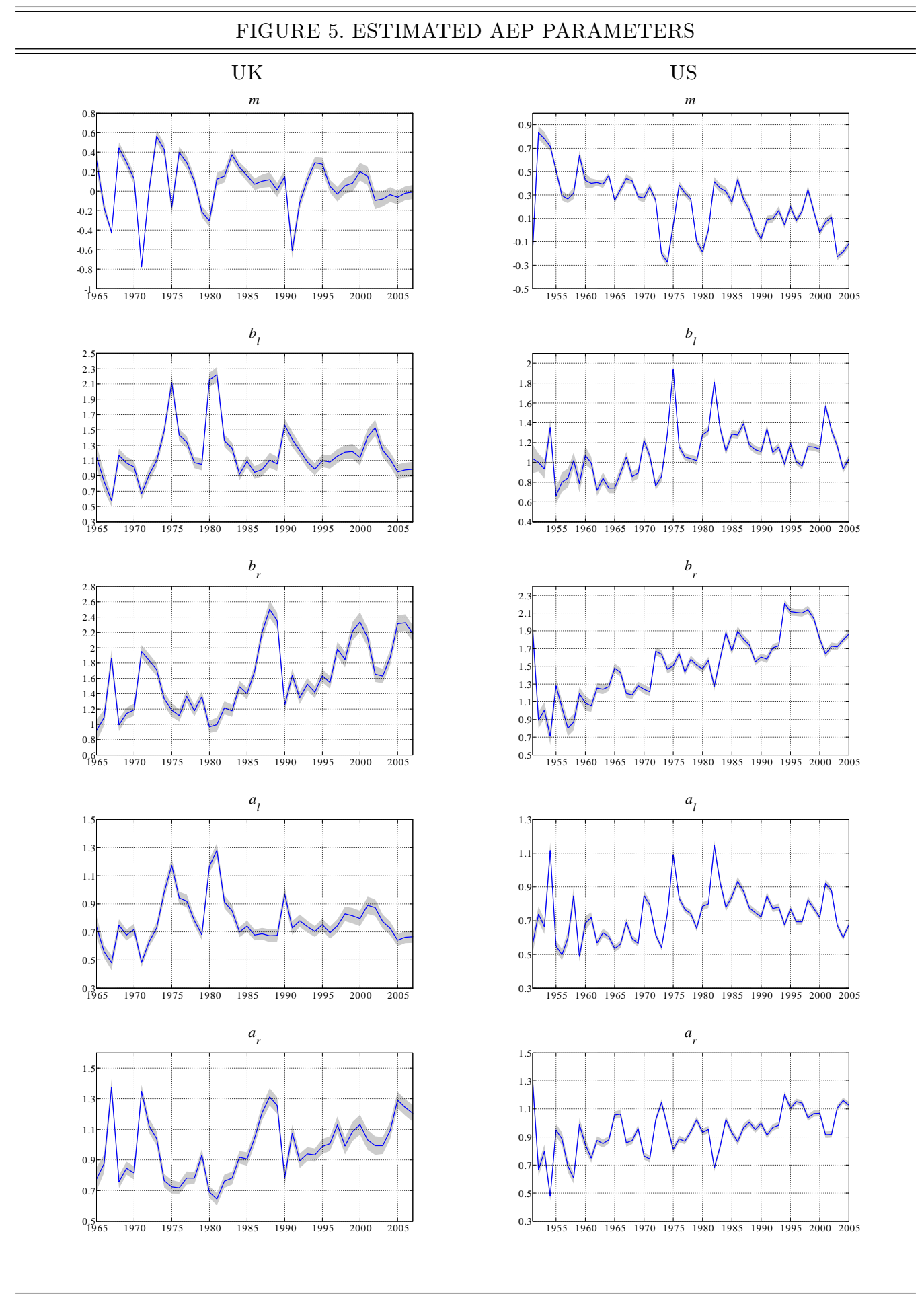

Notes: The figures report the estimated AEP parameters together with the $68 \%$ confidence interval. 


\begin{tabular}{|c|c|c|c|c|}
\hline \multicolumn{5}{|c|}{ TABLE 1a. SUMMARY STATISTICS: EMPIRICAL MOMENTS - UK } \\
\hline & \multicolumn{3}{|c|}{ GDP Growth } & \multirow[t]{2}{*}{ Time Trend } \\
\hline & Corr. & Dyn. Corr. & Conc. & \\
\hline Mean & 0.8161 & 0.8534 & 0.6977 & $0.0009^{*}$ \\
\hline Standard Deviation & -0.1312 & -0.3092 & 0.4419 & $0.0016^{* * *}$ \\
\hline Skewness & -0.5100 & -0.6052 & 0.3023 & $-0.0059^{* * *}$ \\
\hline Kurtosis & 0.1729 & 0.3734 & 0.5349 & $-0.0410^{* * *}$ \\
\hline \multicolumn{5}{|c|}{ TABLE 1b. SUMMARY STATISTICS: EMPIRICAL MOMENTS - US } \\
\hline & \multicolumn{3}{|c|}{ GDP Growth } & Time Trend \\
\hline & Corr. & Dyn. Corr. & Conc. & \\
\hline Mean & 0.7905 & 0.8490 & 0.7818 & $-0.0005^{*}$ \\
\hline Standard Deviation & -0.2514 & -0.3730 & 0.3636 & $0.0014^{* * *}$ \\
\hline Skewness & -0.1928 & -0.1077 & 0.5091 & $-0.0067^{* * *}$ \\
\hline Kurtosis & 0.2382 & 0.3947 & 0.6545 & $-0.0378^{* * *}$ \\
\hline
\end{tabular}

Notes: Corr. is the correlation of the moment with the real GDP growth rate. Dyn. Corr. is a measure of dynamic correlation (Croux et al., 2001), which measures correlation at a specific frequency band: in the present case we choose the business cycle frequency in the range $[\pi / 4,3 \pi / 4]$, which corresponds to a cycle of $6-32$ quarters. Conc. stands for the business cycle concordance indicator of Harding and Pagan (1999). ${ }^{30}$ The variable is entered as linearly detrended whenever the trend is found statistically significant at the $5 \%$ level. ${ }^{31}$ The time trend is the estimated coefficient of a linear trend. ${ }^{* *} /{ }^{* *} /{ }^{*}$ indicates significance at the $1 / 5 / 10 \%$ level.

\footnotetext{
${ }^{30}$ This indicator is bounded between 0 and 1 and indicates independence between the series whenever it equals 0.5.

${ }^{31}$ The resulting measures hardly change if we compute them from the original (i.e., non detrended) variables.
} 


\begin{tabular}{|c|c|c|c|c|c|c|c|c|c|}
\hline \multicolumn{10}{|c|}{ TABLE 2. PAIRWISE CORRELATIONS: AEP PARAMETERS } \\
\hline \multicolumn{5}{|c|}{ UK } & \multicolumn{5}{|c|}{ US } \\
\hline & $m$ & $b_{l}$ & $b_{r}$ & $a_{l}$ & & $m$ & $b_{l}$ & $b_{r}$ & $a_{l}$ \\
\hline$b_{l}$ & 0.0827 & & & & $b_{l}$ & -0.2091 & & & \\
\hline$b_{r}$ & -0.2200 & -0.4155 & & & $b_{r}$ & -0.5541 & 0.1928 & & \\
\hline$a_{l}$ & 0.2435 & 0.9663 & -0.4423 & & $a_{l}$ & 0.0698 & 0.8950 & 0.0611 & \\
\hline$a_{r}$ & -0.4313 & -0.6322 & 0.9027 & -0.7027 & $a_{r}$ & -0.6319 & -0.2249 & 0.8082 & -0.4730 \\
\hline
\end{tabular}

\begin{tabular}{|c|c|c|c|c|}
\hline \multicolumn{5}{|c|}{ TABLE 3a. SUMMARY STATISTICS: AEP PARAMETERS - UK } \\
\hline & \multicolumn{3}{|c|}{ GDP Growth } & Time Trend \\
\hline & Corr. & Dyn. Corr. & Conc. & \\
\hline$m$ & 0.4268 & 0.5164 & 0.8140 & $-0.0038^{*}$ \\
\hline$b_{l}$ & -0.6520 & -0.6950 & 0.3488 & -0.0008 \\
\hline$b_{r}$ & 0.4360 & 0.4257 & 0.6047 & $0.0241^{* * *}$ \\
\hline$a_{l}$ & -0.5664 & -0.6149 & 0.3488 & -0.0004 \\
\hline$a_{r}$ & 0.4262 & 0.3968 & 0.6279 & $0.0077^{* * *}$ \\
\hline \multicolumn{5}{|c|}{ TABLE 3b. SUMMARY STATISTICS: AEP PARAMETERS - US } \\
\hline & \multicolumn{3}{|c|}{ GDP Growth } & Time Trend \\
\hline & Corr. & Dyn. Corr. & Conc. & \\
\hline$m$ & 0.1298 & 0.0804 & 0.4545 & $-0.0093^{* * *}$ \\
\hline$b_{l}$ & -0.6384 & -0.7299 & 0.2909 & $0.0061^{* * *}$ \\
\hline$b_{r}$ & 0.6069 & 0.6375 & 0.6727 & $0.0182^{* * *}$ \\
\hline$a_{l}$ & -0.6099 & -0.6653 & 0.2545 & $0.0027^{* *}$ \\
\hline$a_{r}$ & 0.6520 & 0.6612 & 0.8182 & $0.0051^{* * *}$ \\
\hline
\end{tabular}

Notes: See notes to Table 1. 


\begin{tabular}{|c|c|c|c|c|c|}
\hline \multicolumn{3}{|c|}{ UK } & \multicolumn{3}{|c|}{ US } \\
\hline & $\Delta y \Longrightarrow x$ & $x \Longrightarrow \Delta y$ & & $\Delta y \Longrightarrow x$ & $x \Longrightarrow \Delta y$ \\
\hline Mean & $14.2984^{* * *}$ & 4.2674 & Mean & $6.6815^{* *}$ & 0.9748 \\
\hline Standard Deviation & $22.8803^{* * *}$ & $6.0258^{*}$ & Standard Deviation & 3.7489 & 2.7359 \\
\hline Skewness & $22.7939^{* * *}$ & 4.0710 & Skewness & $4.7447^{* *}$ & $35.9663^{* * *}$ \\
\hline Kurtosis & $34.5884^{* * *}$ & 1.1472 & Kurtosis & $8.0947^{* *}$ & 3.7618 \\
\hline
\end{tabular}

Notes: Table 4 reports bivariate Granger Causality tests: $x$ alternatively represents each of the variables in the first column, while $\Delta y$ denotes the growth rate of real GDP. In general, $z \Longrightarrow h$ indicates Granger Causality from $z$ to $h$ (i.e., $z$ can help at forecasting $h$ ). The bivariate system is estimated by GMM. We retrieve Wald statistics by including two lags of each variable. ${ }^{32}$ Variables $x$ are linearly detrended, whenever a linear trend is found significant at the $5 \%$ level of significance. ${ }^{33}{ }^{* * *} /{ }^{* *} /{ }^{*}$ indicates significance at the $1 / 5 / 10 \%$ level.

\begin{tabular}{|c|c|c|c|c|c|}
\hline \multicolumn{6}{|c|}{ TABLE 5. GRANGER CAUSALITY TESTS: AEP PARAMETERS } \\
\hline \multicolumn{3}{|c|}{$\mathrm{UK}$} & \multicolumn{3}{|c|}{ US } \\
\hline & $\Delta y \Longrightarrow x$ & $x \Longrightarrow \Delta y$ & & $\Delta y \Longrightarrow x$ & $x \Longrightarrow \Delta y$ \\
\hline$m$ & $7.0216^{* *}$ & 0.4550 & $m$ & 1.3301 & $29.0627^{* * *}$ \\
\hline$b_{l}$ & $31.4829^{* * *}$ & 4.4179 & $b_{l}$ & 1.3384 & 4.1889 \\
\hline$b_{r}$ & 3.3028 & $14.2281^{* * *}$ & $b_{r}$ & $5.1507^{*}$ & 0.1729 \\
\hline$a_{l}$ & $21.7935^{* * *}$ & 2.3496 & $a_{l}$ & 0.0397 & $29.9470^{* * *}$ \\
\hline$a_{r}$ & 2.5469 & $10.6939^{* * *}$ & $a_{r}$ & 0.6669 & $16.0716^{* * *}$ \\
\hline
\end{tabular}

Notes: See notes to Table 4.

\footnotetext{
${ }^{32}$ We have also tried different lag structures. The results are virtually unchanged if the test is computed by including 1 or 3 lags for each variable.

${ }^{33}$ The resulting statistics hardly change if the regression comprises the original variables (i.e., non detrended) and a linear trend, whenever this is found significant at the $5 \%$ level in Table 1.
} 


\begin{tabular}{cccccc}
\hline \hline \multicolumn{5}{c}{ TABLE 6. AEP PARAMETERS AND FINANCIAL FRICTIONS - US } \\
\hline \hline \multirow{3}{*}{ Const. } & $m$ & $b_{l}$ & $b_{r}$ & $a_{l}$ & $a_{r}$ \\
\cline { 2 - 6 } & 0.4526 & 0.2601 & 0.6592 & 0.3503 & 0.8912 \\
$t$ & $(0.0008)$ & $(0.3015)$ & $(0.0000)$ & $(0.0383)$ & $(0.0000)$ \\
& -0.0052 & -0.0011 & 0.0118 & 0.0004 & 0.0068 \\
$x_{t-1}$ & $(0.0038)$ & $(0.7655)$ & $(0.0018)$ & $(0.8517)$ & $(0.0000)$ \\
& 0.6360 & 0.1334 & 0.3664 & 0.2010 & 0.1625 \\
$x_{t-2}$ & $(0.0000)$ & $(0.2213)$ & $(0.0085)$ & $(0.0601)$ & $(0.2493)$ \\
& $(0.4131$ & 0.1407 & 0.0741 & -0.0111 & -0.1904 \\
EFP & $(0.000)$ & $(0.4062)$ & $(0.5816)$ & $(0.9362)$ & $(0.1602)$ \\
& -0.0771 & 0.3224 & -0.0797 & 0.1321 & -0.0705 \\
& $(0.3441)$ & $(0.0305)$ & $(0.2997)$ & $(0.0852)$ & $(0.1303)$
\end{tabular}

Notes: The table reports the estimated coefficients and the associated p-values (in parenthesis). We estimate the regression by GMM, with Newey-West heteroskedasticity-robust standard errors. 


\section{Appendix A: Additional Results from the $+/-100 \%$ Truncated Sample}

\begin{tabular}{ccccc}
\hline \hline TABLE A1a. SUMMARY STATISTICS: EMPIRICAL MOMENTS - UK \\
\hline \hline \multirow{4}{*}{ Mean } & 0.8090 & 0.8447 & 0.7209 & $0.0015^{* *}$ \\
\cline { 2 - 5 } Corr. & Dyn. Corr. & Conc. & Time Trend \\
\cline { 2 - 5 } Standard Deviation & 0.2651 & 0.1203 & 0.6512 & $0.0039^{* * *}$ \\
Skewness & 0.1780 & 0.0761 & 0.5581 & $-0.0131^{* *}$ \\
Kurtosis & 0.1543 & 0.4939 & 0.5349 & $-0.0957^{* * *}$ \\
\hline \hline TABLE A1b. SUMMARY STATISTICS: EMPIRICAL MOMENTS - US \\
\hline \hline \multicolumn{5}{c}{ GDP Growth } \\
\cline { 2 - 4 } & Corr. & Dyn. Corr. & Conc. \\
\cline { 2 - 4 } Mean & 0.7482 & 0.8310 & 0.7636 & -0.0004 \\
Standard Deviation & -0.0667 & -0.2003 & 0.4545 & $0.0028^{* * *}$ \\
Skewness & 0.2057 & 0.1970 & 0.4909 & $-0.0186^{* * *}$ \\
Kurtosis & 0.0604 & 0.1154 & 0.5636 & $-0.0723^{* * *}$ \\
\hline
\end{tabular}

Notes: Corr. stands for the correlation coefficient of the variable of interest with the real GDP growth rate. Dyn. Corr. is the measure of dynamic correlation of Croux et al. (2001), which measures correlation at a specific frequency band: in the present case we choose the business cycle frequency in the range $[\pi / 4,3 \pi / 4]$, which corresponds to a cycle of $6-32$ quarters. Conc. stands for the business cycle concordance indicator of Harding and Pagan (1999). ${ }^{34}$ The variable is entered as linearly detrended whenever the trend is found statistically significant at the $5 \%$ level. $^{35}$ Time trend reports the estimated coefficient of a linear trend. ${ }^{* * *} /{ }^{* *} /{ }^{*}$ indicates significance at the $1 / 5 / 10 \%$ level.

\footnotetext{
${ }^{34}$ This indicator is bounded between 0 and 1 and indicates independence between the series whenever it equals 0.5 .

${ }^{35}$ The resulting measures hardly change if we compute them from the original (i.e., non detrended) variables.
} 


\begin{tabular}{|c|c|c|c|c|c|c|c|c|c|}
\hline \multicolumn{10}{|c|}{ TABLE A2. PAIRWISE CORRELATIONS: AEP PARAMETERS } \\
\hline & \multicolumn{4}{|c|}{ UK } & \multicolumn{5}{|c|}{ US } \\
\hline & $m$ & $b_{l}$ & $b_{r}$ & $a_{l}$ & \multirow[b]{2}{*}{$b_{l}$} & $m$ & $b_{l}$ & $b_{r}$ & $a_{l}$ \\
\hline$b_{l}$ & 0.1836 & & & & & 0.0402 & & & \\
\hline$b_{r}$ & -0.5004 & -0.5263 & & & $b_{r}$ & -0.7094 & -0.0764 & & \\
\hline$a_{l}$ & 0.0780 & 0.9183 & -0.3485 & & $a_{l}$ & -0.0943 & 0.7956 & 0.0934 & \\
\hline$a_{r}$ & -0.4960 & -0.7109 & 0.8828 & -0.6524 & $a_{r}$ & -0.5209 & -0.4038 & 0.7597 & -0.5139 \\
\hline
\end{tabular}

\begin{tabular}{ccccc}
\hline \hline \multicolumn{4}{c}{ TABLE A3a. SUMMARY STATISTICS: AEP PARAMETERS - UK } \\
\hline \hline \multicolumn{3}{c}{ GDP Growth } \\
\cline { 2 - 4 }$m$ & Corr. & Dyn. Corr. & Conc. & Time Trend \\
\cline { 2 - 4 }$b_{l}$ & -0.4364 & 0.5311 & 0.7209 & -0.0011 \\
$b_{r}$ & 0.1244 & -0.5387 & 0.3256 & -0.0029 \\
$a_{l}$ & -0.6337 & -0.6616 & 0.3256 & $0.0077^{* * *}$ \\
$a_{r}$ & 0.3028 & 0.1666 & 0.5814 & 0.0000 \\
\hline \hline TABLE A3b. SUMMARY STATISTICS: AEP PARAMETERS - US \\
\hline \hline \multicolumn{5}{c}{$0.0030^{*}$} \\
\cline { 2 - 4 }$m$ & 0.2230 & 0.1660 & 0.4727 & $-0.0081^{* * *}$ \\
$b_{l}$ & -0.5707 & -0.6511 & 0.2545 & 0.0009 \\
$b_{r}$ & 0.3924 & 0.4739 & 0.7455 & $0.0071^{* * *}$ \\
$a_{l}$ & -0.6092 & -0.6685 & 0.2727 & $0.0019^{* *}$ \\
$a_{r}$ & 0.5961 & 0.5936 & 0.7818 & $0.0024^{* *}$ \\
\hline
\end{tabular}

Notes: See notes to Table A1. 


\begin{tabular}{|c|c|c|c|c|c|}
\hline \multicolumn{3}{|c|}{$\overline{\mathrm{UK}}$} & \multicolumn{3}{|c|}{ US } \\
\hline & $\Delta y \Longrightarrow x$ & $x \Longrightarrow \Delta y$ & & $\Delta y \Longrightarrow x$ & $x \Longrightarrow \Delta y$ \\
\hline Mean & $10.5724^{* * *}$ & 3.0310 & Mean & $6.7454^{* *}$ & 0.7117 \\
\hline Standard Deviation & $7.4424^{* *}$ & 1.9346 & Standard Deviation & 3.3634 & 3.9000 \\
\hline Skewness & 2.8436 & 2.4767 & Skewness & 0.3672 & $31.5676^{* * *}$ \\
\hline Kurtosis & $28.0487^{* * *}$ & 1.3218 & Kurtosis & 1.6686 & 0.3669 \\
\hline
\end{tabular}

Notes: Table A4 reports bivariate Granger Causality tests: $x$ alternatively represents each of the variables in the first column, while $\Delta y$ denotes the growth rate of real GDP. In general, $z \Longrightarrow h$ indicates Granger Causality from $z$ to $h$ (i.e., $z$ can help at forecasting $h$ ). The bivariate system is estimated by GMM. We retrieve Wald statistics by including two lags of each variable. ${ }^{36}$ Variables $x$ are linearly detrended, whenever a linear trend is found significant at the $5 \%$ level of significance. ${ }^{37 * * *} /{ }^{* *} /{ }^{*}$ indicates significance at the $1 / 5 / 10 \%$ level.

\begin{tabular}{|c|c|c|c|c|c|}
\hline \multicolumn{6}{|c|}{ TABLE A5. GRANGER CAUSALITY TESTS: AEP PARAMETER } \\
\hline \multicolumn{3}{|c|}{ UK } & \multicolumn{3}{|c|}{ US } \\
\hline & $\Delta y \Longrightarrow x$ & $x \Longrightarrow \Delta y$ & & $\Delta y \Longrightarrow x$ & $x \Longrightarrow \Delta y$ \\
\hline$m$ & $10.3056^{* * *}$ & 0.5237 & $m$ & 2.9491 & $9.5208^{* * *}$ \\
\hline$b_{l}$ & $14.8114^{* * *}$ & 3.6558 & $b_{l}$ & 0.2924 & 3.8248 \\
\hline$b_{r}$ & $9.5450^{* * *}$ & 1.1592 & $b_{r}$ & 2.1017 & 0.0688 \\
\hline$a_{l}$ & $16.0996^{* * *}$ & 2.1006 & $a_{l}$ & 0.0391 & $16.4799^{* * *}$ \\
\hline$a_{r}$ & $8.3520^{* *}$ & $4.4450^{*}$ & $a_{r}$ & 3.0324 & $15.0175^{* * *}$ \\
\hline
\end{tabular}

Notes: See notes to Table A4.

\footnotetext{
${ }^{36}$ We have also tried different lag structures. The results are virtually unchanged if the test is computed by including 1 or 3 lags for each variable.

${ }^{37}$ The resulting statistics hardly change if the regression comprises the original variables (i.e., non detrended) and a linear trend, whenever this is found significant at the $5 \%$ level in Table 1.
} 


\begin{tabular}{cccccc}
\hline \hline \multicolumn{6}{c}{ TABLE A6. AEP PARAMETERS AND FINANCIAL FRICTIONS - US } \\
\hline \hline \multirow{3}{*}{ Const. } & $m$ & $b_{l}$ & $b_{r}$ & $a_{l}$ & $a_{r}$ \\
\cline { 2 - 6 } & 0.4530 & 0.4572 & 0.4713 & 0.2528 & 0.7910 \\
$t$ & $(0.0018)$ & $(0.0152)$ & $(0.0000)$ & $(0.0773)$ & $(0.0000)$ \\
& -0.0054 & -0.0022 & 0.0044 & -0.0003 & 0.0041 \\
$x_{t-1}$ & $(0.0006)$ & $(0.2413)$ & $(0.0145)$ & $(0.8355)$ & $(0.0001)$ \\
& 0.3603 & 0.1467 & 0.4849 & 0.2507 & 0.2322 \\
$x_{t-2}$ & $(0.0378)$ & $(0.4647)$ & $(0.0003)$ & $(0.0356)$ & $(0.0520)$ \\
& -0.2347 & 0.0533 & -0.0155 & 0.0300 & -0.2531 \\
EFP $P_{t}$ & $(0.0568)$ & $(0.7896)$ & $(0.9224)$ & $(0.8341)$ & $(0.0681)$ \\
& -0.0848 & 0.1623 & -0.0150 & 0.1079 & -0.0617 \\
& $(0.2613)$ & $(0.0514)$ & $(0.7625)$ & $(0.0963)$ & $(0.1104)$ \\
& & & & &
\end{tabular}

Notes: Table A6 reports estimated coefficients and the associated p-values (in parenthesis). We estimate the regression by GMM, with Newey-West heteroskedasticity-robust standard errors. 


\section{Appendix B: Scaling Behavior}

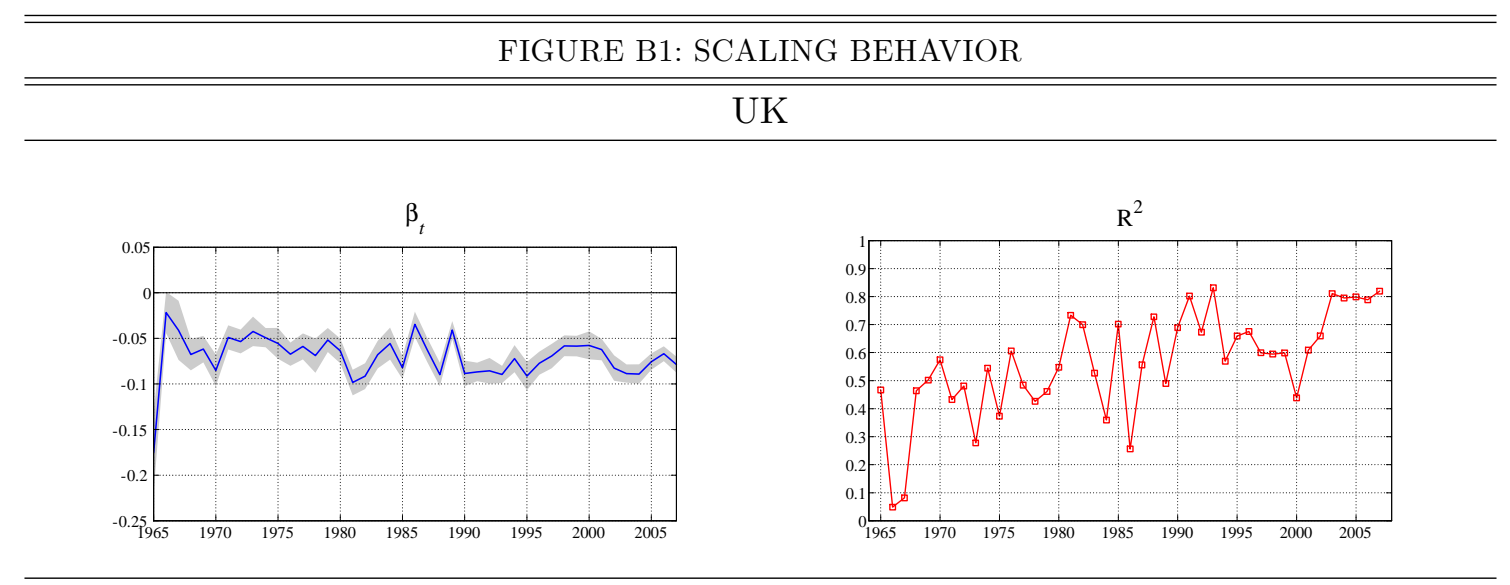

US
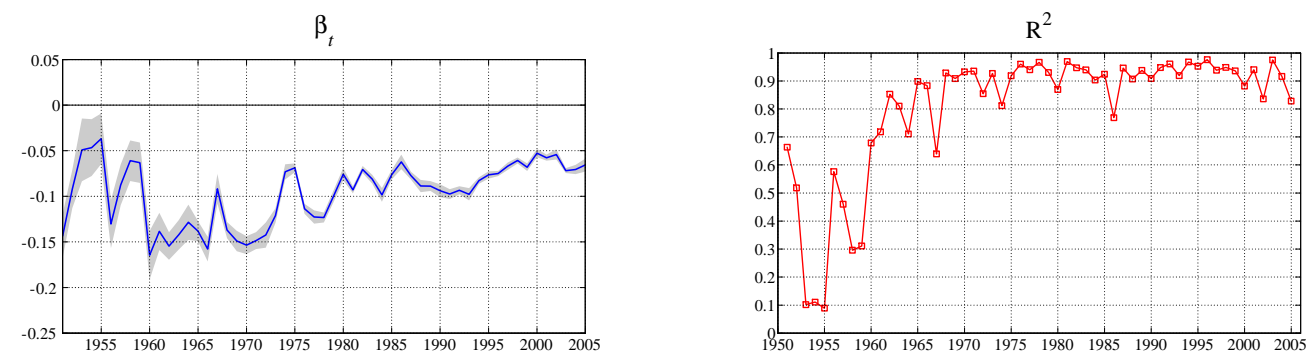

Notes: Panels on the LHS of the figure are estimates of the scaling parameter $\left(\hat{\beta}_{t}\right)$ with the associated $68 \%$ confidence interval. On the RHS we report goodness-of-fit measures for each regression. 


\section{Appendix C: Technical Discussion of the Two-stage Estimation Strategy}

The two-stage strategy we employ consists of first estimating the AEP density in each year and then extracting time series for the parameters. It might be argued that estimating the AEP parameters and their dynamics simultaneously would be more efficient, or that using estimated regressors might bias our results. Unfortunately, the complexity of the problem we face renders the one stage estimation unfeasible. This is mainly due to the fact that the log-likelihood function is not well behaved. Bottazzi (2004) shows that the log-likelihood typically displays many local maxima and that differentiating among them is not an easy task.

In this appendix we discuss how to obtain consistent and asymptotically efficient estimates with our two-stage approach. The main problem potentially relates to the presence of measurement errors in the estimated parameters (see, e.g., Pagan, 1984). As explained above, in the first stage we estimate the parameters of the AEP distribution by maximum likelihood (ML). Bottazzi and Secchi (2006b) demonstrate that ML estimates are consistent and normally distributed. Furthermore, they report extensive evidence that any bias in the estimation of the AEP parameters disappears even for relatively small sized samples. ${ }^{38}$ Nevertheless, a problem might arise in the second stage, when using generated regressors to perform time series analysis. It might be argued that the estimated regressor is a noisy observation of the true unobservable AEP parameter. ${ }^{39}$ Let us indicate with $\widehat{x}_{t}$ the estimated parameter of interest, and let us assume it as a noisy observation of the true underlying process of the parameter:

$$
\widehat{x}_{t}=x_{t}^{*}+\eta_{t}
$$

We then use the estimated parameter in a hypothetical dynamic regression. Specifically, let us assume that the true underlying process is an $\operatorname{ARX}(1,1)$ :

$$
x_{t}^{*}=\rho x_{t-1}^{*}+\gamma y_{t-1}+e_{t}
$$

Clearly, we deal with an unobservable variable problem examined, for instance, by Zellner (1970). After substituting for the estimated parameter we obtain:

$$
\begin{aligned}
\widehat{x}_{t} & =\rho \widehat{x}_{t-1}+\gamma y_{t-1}+\varepsilon_{t} \\
\varepsilon_{t} & =e_{t}+\eta_{t}-\rho \eta_{t-1}
\end{aligned}
$$

the standard OLS estimate is therefore inconsistent, given that $E\left(\widehat{x}_{t-1} \varepsilon_{t}\right) \neq 0$.

Suppose that we can find an instrument for $\widehat{x}_{t-1}$ which is uncorrelated with the noise. Then the standard two-stage estimator is unbiased. Furthermore, this is asymptotically efficient and, indeed, no asymptotic gains are available by switching to a full MLE (Pagan, 1984). It turns out that a natural instrument can be easily obtained by randomly drawing two subsamples from the original sample and then estimating the AEP parameters for each of these samples. An estimate for the whole sample is given by the simple average of the two estimates. Clearly this is also an approximation of the original true value (and it is an inefficient one). However, in

\footnotetext{
${ }^{38}$ In fact, any bias disappears for $n>100$, which is well below the lowest sample size considered in this paper.

${ }^{39} \mathrm{It}$ is worth recalling that the size of the problem we are discussing can be related to the noise-to-signal ratio in the estimation. Clearly, given the precision with which we estimate the parameters, and the fact that we deal with consistent estimators, the problem we discuss is bound to be marginal for the case under analysis.
} 
principle the approximation error in this case should not be correlated with the one that arises from the efficient estimate. Therefore, the inefficient estimate is a perfect instrument for our purpose (Fuller, 1987).

The reasoning above would suggest resorting to a IV procedure. However, the asymptotic variance of the IV estimator is always larger and sometimes much greater than that of the OLS estimator. Therefore, turning to IV for the sake of consistency must be balanced against the inevitable loss of efficiency. Furthermore, IV estimates can have very poor small sample properties and, given that we have a small sample, it may be advisable to use OLS. The Hausman test helps at balancing the loss of efficiency entailed by the IV estimation with the bias and inconsistency of the OLS estimators. ${ }^{40}$ Tables C1 and C2 report the results for the Hausman-Wu test and the Durbin-Hausman test for each of the estimated AEP parameters. The null hypothesis is always rejected at usual confidence levels. We conclude that the potential endogeneity problem that arises when using estimated regressors is of little harm in our case. Therefore, the estimated parameters in the main text are always treated as the true underlying values. $^{41}$

\begin{tabular}{|c|c|c|c|c|c|}
\hline \multicolumn{6}{|c|}{ TABLE C1. HAUSMAN TESTS } \\
\hline \multicolumn{3}{|c|}{ UK } & \multicolumn{3}{|c|}{ US } \\
\hline & $H-W$ & $D-H$ & & $H-W$ & $D-H$ \\
\hline$m$ & 0.9566 & 0.9545 & $m$ & 0.9086 & 0.9058 \\
\hline$b_{l}$ & 0.9863 & 0.9856 & $b_{l}$ & 0.1854 & 0.2109 \\
\hline$b_{r}$ & 0.8106 & 0.8086 & $b_{r}$ & 0.3836 & 0.4053 \\
\hline$a_{l}$ & 0.2618 & 0.2896 & $a_{l}$ & 0.6390 & 0.6368 \\
\hline$a_{r}$ & 0.6335 & 0.6507 & $a_{r}$ & 0.3877 & 0.4005 \\
\hline
\end{tabular}

Notes: Table $\mathrm{C} 1$ reports the p-values associated with the Hausman-Wu $(H-W)$ test, as well the DurbinHausman $(D-H)$ The test is performed on the estimated coefficients of the $\operatorname{AR}(2)$ model for each of the estimated AEP parameters. Choosing 1 or 3 lags delivers very similar results. The null hypothesis is that there is no gain from IV estimation. For a standard regression with $K$ regressors and $K^{*}$ restrictions, the Hausman - Wu statistic is distributed as a $F\left(K^{*}, T-K-K^{*}\right)$, whereas the Durbin-Hausman test is distributed as a $\chi^{2}\left(K^{*}\right)$.

\footnotetext{
${ }^{40}$ The Hausman test involves fitting the model by both IV and OLS, thus comparing a weighted square of the difference between the two estimators.

${ }^{41}$ Nevertheless, we still use the GMM estimator with NW standard errors to correct for possible heteroskedasticity and autocorrelation in the error terms.
} 


\begin{tabular}{|c|c|c|c|c|c|}
\hline \multicolumn{6}{|c|}{ TABLE C2. HAUSMAN TESTS } \\
\hline \multicolumn{3}{|c|}{ UK } & \multicolumn{3}{|c|}{ US } \\
\hline & $H-W$ & $D-H$ & & $H-W$ & $D-H$ \\
\hline$m$ & 0.8661 & 0.8622 & $m$ & 0.9805 & 0.9796 \\
\hline$b_{l}$ & 0.9340 & 0.9313 & $b_{l}$ & 0.2080 & 0.2390 \\
\hline$b_{r}$ & 0.5705 & 0.5939 & $b_{r}$ & 0.3388 & 0.3855 \\
\hline$a_{l}$ & 0.1075 & 0.1520 & $a_{l}$ & 0.6034 & 0.6072 \\
\hline$a_{r}$ & 0.7149 & 0.7299 & $a_{r}$ & 0.4169 & 0.4319 \\
\hline
\end{tabular}

Notes: Table $\mathrm{C} 2$ reports the p-values for the Hausman-Wu $(H-W)$ and Durbin-Hausman $(D-H)$ tests. The test is performed on an $\operatorname{ARX}(2,2)$ model for each of the estimated AEP parameters, with two lags of the GDP growth rate (this regression is analogous to that employed in the Granger Causality test reported in the main text). 